\title{
U.S. Geological Survey Science-Improving the Value of the Chesapeake Bay Watershed
}

\section{Congress directed the Federal Government to work with States to restore the Nation's largest estuary.}

Chesapeake Bay restoration provides important economic and ecological benefits:

- 18 million people live and work in the Bay watershed and enjoy its benefits.

- 3,600 types of fish, wildlife, and plants underpin the economic value of the Bay ecosystem.

- Poor water quality and habitat loss threaten restoration and negatively impact the economy.

- 10 Goals to meet by 2025 through the Chesapeake Bay Program, a voluntary partnership.

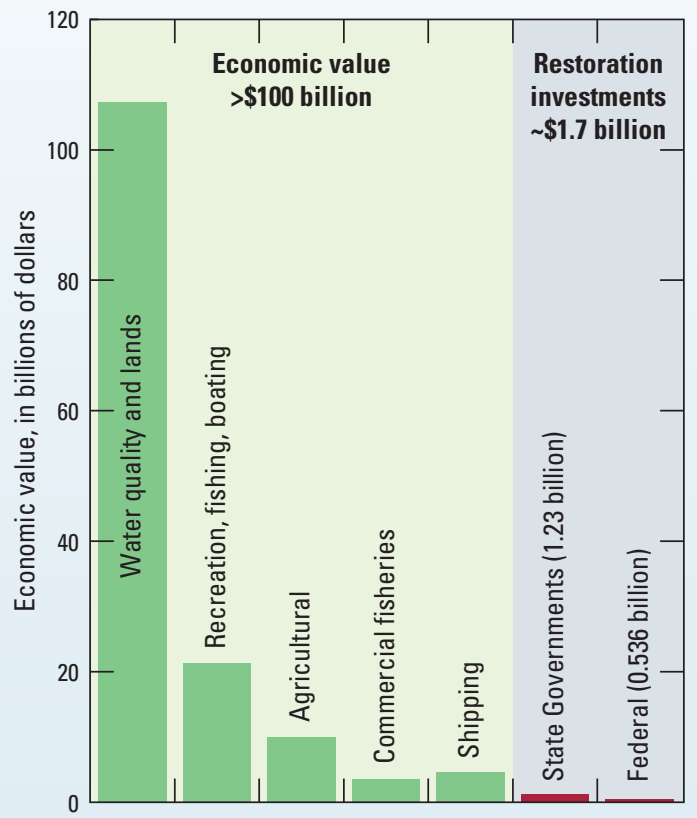

Annual economic value and restoration investments. Sources: Phillips and McGee, 2014; U.S. Army Corps of Engineers, 2015; and Office of Management and Budget, 2016.

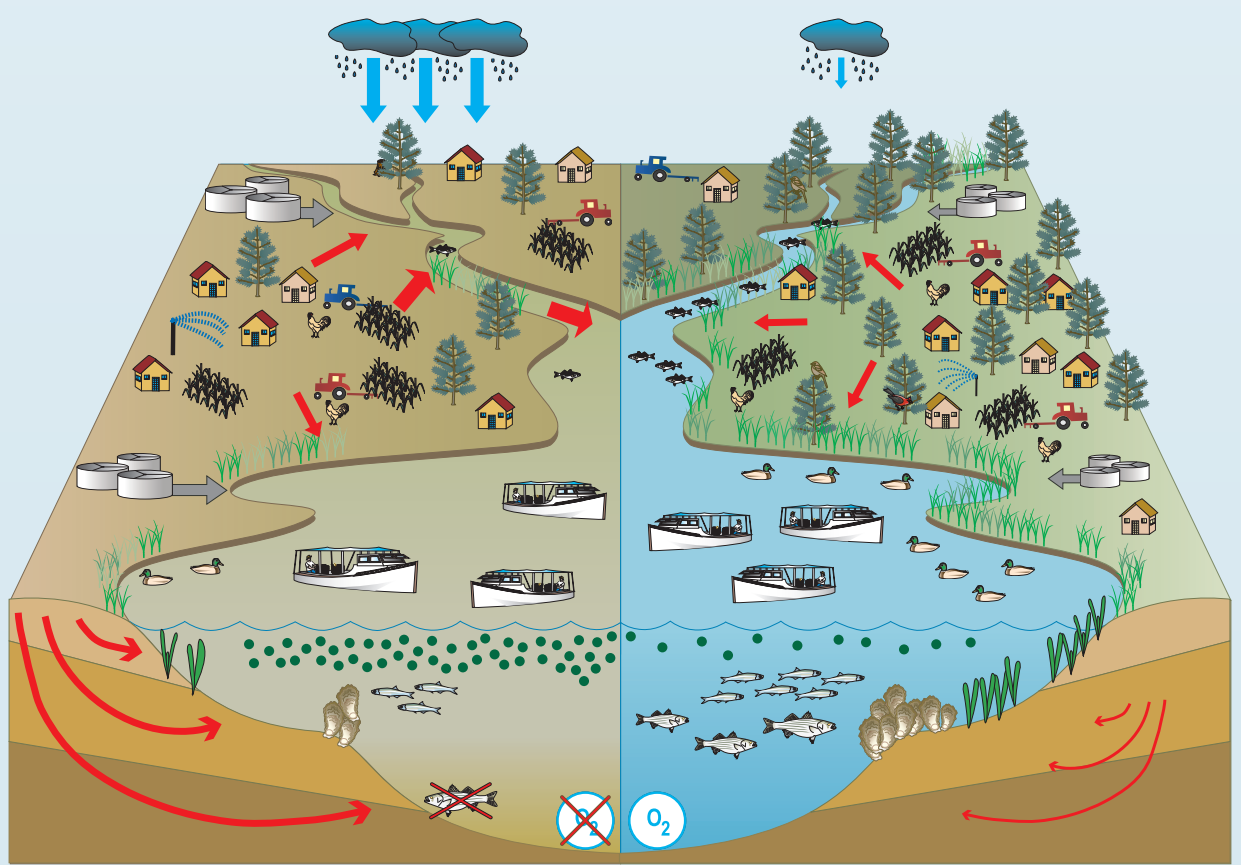

(Modified from Phillips, 2006)

Present

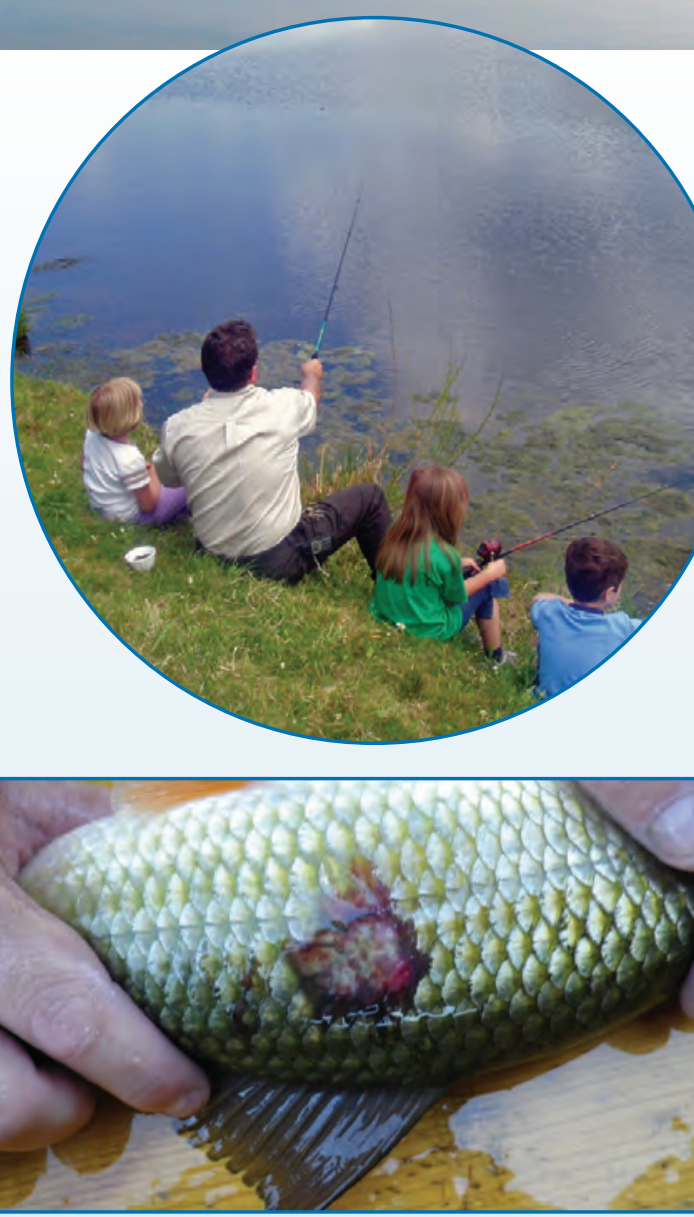

Photograph credits: Top; A boat floating on Chesapeake Bay, by Jane Hawkey, IAN Image Library (www.ian.umces. edu/imagelibrary//.Middle; A family fishing, by U.S. Fish and Wildlife Service. Bottom; Unhealthy fish, by USGS

USGS science is the foundation to assess progress and focus resources where they are most effective.

- Partners use our science every day.

- We monitor and analyze:

- Fish, wildlife, and habitat

- Water quality

- Land-use and environmental change

- USGS spends \$12M on science activities, which is provided by multiple USGS programs.

- Our science helps improve the Chesapeake Bay watershed and informs other national efforts. 


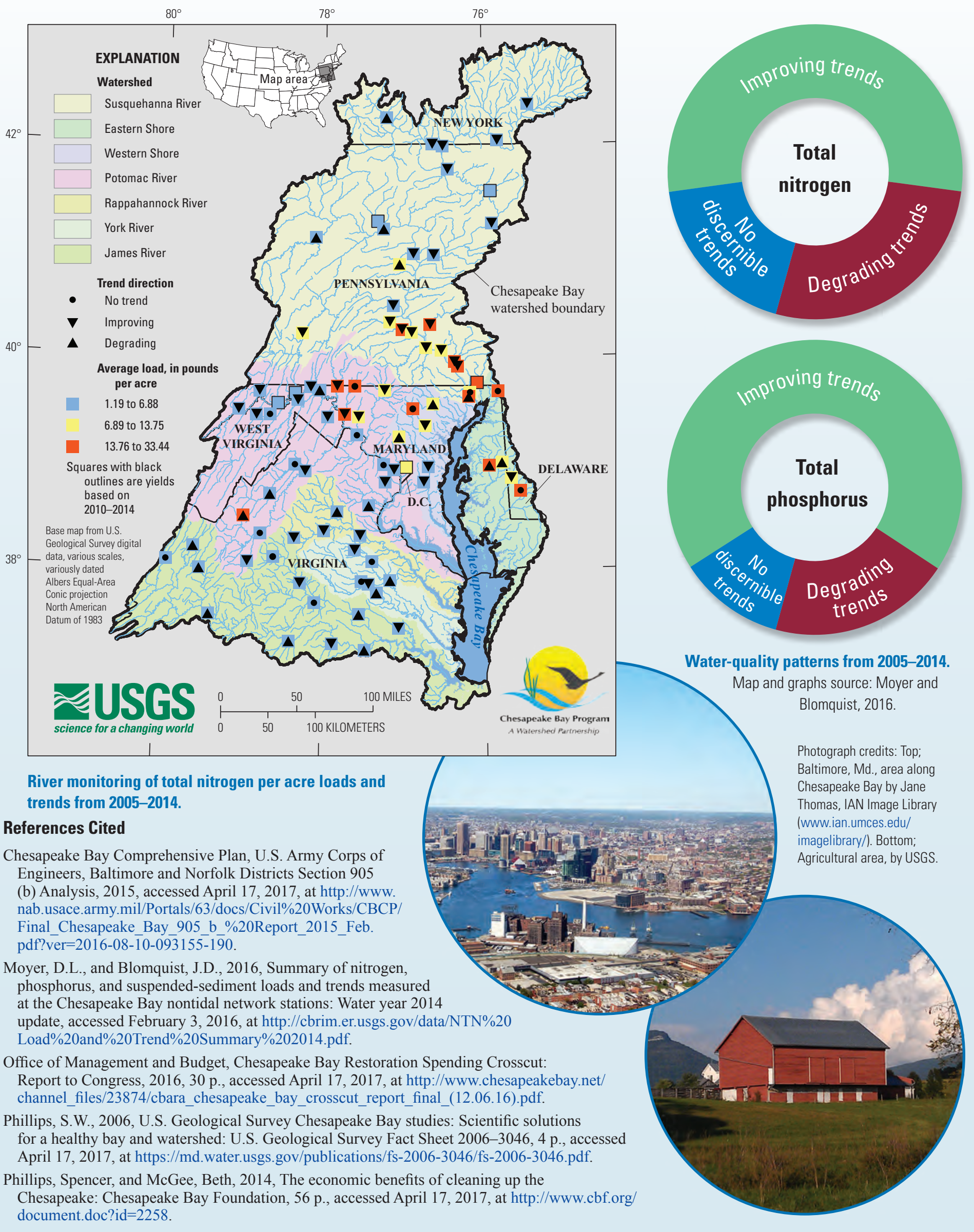

By Scott Phillips (swphilli@usgs.gov),

Kenneth Hyer (kenhyer@usgs.gov), and

Elizabeth Goldbaum (egoldbaum@usgs.gov)
For more information, visit the USGS

Chesapeake Bay Activities website at

https://chesapeake.usgs.gov/
ISSN 2327-6916 (print) ISSN 2327-6932 (online) https://doi.org/10.3133/fs20173031 